ARTIGO

\title{
Notas para a reconstrução da noção de equidade subjacente ao desenho do Paic*
}

\author{
Naira Muylaert a \\ Alicia Maria Catalano de Bonamino ${ }^{b}$ \\ Maria Océlia Mota ${ }^{c}$
}

\section{Resumo}

Esse artigo tem como objetivo analisar o desenho do Prêmio Escola Nota Dez, que faz parte do sistema de incentivos do Programa Aprendizagem na Idade Certa (Paic) do estado do Ceará, à luz dos conceitos de equidade de Rawls e Dubet e dos conceitos de justiça escolar e de discriminação positiva formulados por Crahay e Dubet. Para tanto, são analisados documentos referentes ao Paic, a fim de explicitar como operam esses conceitos na formulação do Prêmio. À luz desses autores, o artigo analisa a forma sui generis de o Prêmio conciliar princípios de meritocracia e de equidade, no âmbito de uma política que, como o Paic, melhora os resultados do desempenho médio dos alunos em Língua Portuguesa e em Matemática, ao mesmo tempo em que consegue reduzir a desigualdade na distribuição social da aprendizagem dentro e entre as escolas das redes municipais de ensino cearenses.

Palavras-chave: Prêmio Escola Nota Dez. Justiça como Equidade. Meritocracia.

\section{Introdução}

O regime de colaboração, entendido como as relações de cooperação entre estados e seus municípios, apresenta um modelo mais institucionalizado e sistêmico no estado do Ceará. Antes mesmo de a Constituição Federal de 1988 estabelecer a colaboração entre os entes federados na oferta de Educação Básica, o Ceará já

\footnotetext{
* Este estudo é produto da pesquisa "Avaliação da implementação do Prêmio Escola Nota Dez e do seu impacto na eficácia e na equidade escolar no Estado de Ceará", sob coordenação da profa. Dra. Alicia Bonamino e realizada com o apoio do Conselho Nacional de Desenvolvimento Científico e Tecnológico - CNPq.

a Pontifícia Universidade Católica do Rio de Janeiro, Rio de Janeiro, RJ, Brasil.

b Pontifícia Universidade Católica do Rio de Janeiro, Rio de Janeiro, RJ, Brasil.

c Prefeitura Municipal de Duque de Caxias, Duque de Caxias, RJ, Brasil.
} 
experimentava, desde meados da década de 1960, uma administração educacional baseada no compartilhamento de responsabilidades, num contexto em que os municípios respondiam por 52,1\% das matrículas do Ensino Fundamental e o estado, por 33,3\% (VIEIRA; VIDAL, 2013).

Essa longa trajetória de colaboração no Ceará explica, em certa medida, o sucesso recente da principal política educacional do estado dirigida ao Ensino Fundamental. Inúmeros indicadores evidenciam a expressiva melhoria da qualidade do Ensino ofertado no Ceará e essa melhoria é atribuída por parte da literatura ao regime de colaboração estabelecido entre o governo do estado e os 184 municípios no âmbito do Programa Alfabetização da Idade Certa (Paic). (SEGATTO, 2015). O Paic envolve duas formas de colaboração. Por um lado, está a colaboração vertical que se estabelece entre o estado e seus municípios; por outro lado, está a colaboração horizontal entre municípios e entre escolas (VIEIRA; VIDAL, 2013).

A ideia de colaboração horizontal consta da resolução $\mathrm{n}^{\circ} 1$ de 23 de janeiro de 2012 do Ministério da Educação, denominada Arranjos de Desenvolvimento da Educação (ADE). Essa resolução tem o objetivo de incentivar alternativas de colaboração entre instâncias federadas, a fim de oferecer "mecanismos capazes de fortalecer o regime de colaboração tanto na esfera vertical (União, estados e municípios) quanto na horizontal entre municípios, tomando como referência a organização territorial do Estado" (BRASIL, 2011, p. 1). Esses arranjos foram concebidos na perspectiva de um trabalho em rede entre municípios com proximidade geográfica e características sociais e econômicas semelhantes, baseado na troca de experiências e na busca de soluções conjuntas para os problemas da Educação, em articulação com os estados e a União.

Na mesma perspectiva dos arranjos, Vieira e Vidal (2013) apontam que, para serem bem-sucedidas, as formas de colaboração precisam considerar as questões territoriais e também a continuidade das formas organizacionais de colaboração vertical e horizontal já estabelecidas. No caso do Ceará, é por meio do Paic que o estado vem aprimorando as formas verticais e horizontais de colaboração existentes, ao desempenhar um papel estratégico na coordenação da atuação educacional dos municípios e das escolas e ao orientar uma colaboração permanente, institucionalizada e sistêmica, se comparada com a maioria dos outros estados brasileiros (SEGATTO; ABRUCIO, 2016).

O Paic é inovador em dois sentidos. Primeiro, porque é uma política formulada pelo governo do estado do Ceará para as redes municipais de Ensino, o que o difere das políticas da maioria dos demais estados que desenham programas 
destinados apenas aos seus próprios sistemas educacionais. Segundo, porque o programa não busca somente contribuir com a melhoria do funcionamento das redes de Ensino e das escolas, mas se propõe, também, a incentivar a cooperação nas relações entre agentes políticos estaduais e municipais ${ }^{1}$ (o executivo estadual e os prefeitos) e entre agentes educacionais das diferentes hierarquias burocráticas envolvidas com o Paic nas coordenadorias regionais, nas Secretarias de Educação e nas escolas. Para sustentar e aprimorar essas formas de colaboração, o governo estadual, por meio do Paic, lança mão de estratégias que envolvem um sistema próprio de avaliação, de informação e de transferências financeiras para os municípios e para as escolas.

O artigo está centrado na discussão do desenho das transferências financeiras do Paic, mais especificamente do seu sistema de incentivos. Como em outros estados, esse repasse é orientado pelo desempenho dos alunos na avaliação estadual, mas, diferentemente de todas as outras experiências estaduais, inclui a previsão de repasses destinados à redução das desigualdades educacionais entre municípios e entre escolas.

O sistema de incentivos do Paic se constitui a partir de dois mecanismos. $\mathrm{O} 1^{\circ} \mathrm{diz}$ respeito ao repasse da cota-parte do Imposto sobre Circulação de Mercadorias e Serviços (ICMS) ${ }^{2}$ às prefeituras e está dirigido aos agentes políticos. Seu objetivo é incentivar os prefeitos a investirem mais recursos na Educação municipal, principalmente entre aqueles que governam cidades com pouca capacidade econômica. $\mathrm{O} 2^{\circ}$ - foco da análise desse estudo - refere-se ao Prêmio Escola Nota Dez e está dirigido às burocracias escolares. Criado em 2009 no âmbito do Paic, o Prêmio representa uma das ações indutoras de bons resultados escolares $\mathrm{e}$, ao mesmo tempo, um mecanismo de apoio às escolas com resultados mais baixos. Sua principal finalidade é disseminar boas práticas pedagógicas e de gestão escolar com o objetivo de melhorar a aprendizagem dos alunos.

\footnotetext{
${ }^{1}$ Esse $2^{\circ}$ elemento se fez presente na elaboração e implementação da política nacional, o Pnaic - Programa Nacional de Alfabetização na Idade Certa, que, inspirado no Paic, procurou induzir a colaboração entre estados e seus municípios sem, contudo, fazer uso de incentivos financeiros como é o caso do programa cearense analisado neste artigo.

${ }^{2}$ Estabelecido pela Lei Estadual no 14.023/2007, a nova regra de rateio do ICMS estabelece que $25 \%$ do total de repasses desse imposto pelo Estado aos municípios devem observar os seguintes critérios: a) $3 / 4$ da quota-parte a serem distribuídos de acordo com o Valor Fiscal Adicionado (VAF) - um recurso atrelado ao ICMS arrecadado dentro do próprio município; b) 1/4 do restante da quota-parte devida deve ser distribuída de acordo com três indicadores setoriais utilizados pelo Governo Estadual, a saber: 1) 18\% de acordo com o Índice de Qualidade da Educação (IQE) um indicador que integra resultados de aprendizagem e fluxo, utilizando a média de proficiência em Língua Portuguesa e em Matemática obtida pelos alunos do $2^{\circ}$ ano e do $5^{\circ}$ ano e a taxa de aprovação dos alunos do $1^{\mathrm{a}}$ ao $5^{\circ}$ ano, nos dois anos antecedentes ao repasse; 2 ) $5 \%$ de acordo com o Índice de Qualidade da Saúde (IQS); 3) 2\% de acordo com o Índice de Qualidade do Meio Ambiente (IQM).
} 
Transitando entre o mérito e a equidade (MOTA, 2018), o Prêmio busca, por um lado, induzir a competição por resultados entre as escolas por meio de repasses de recursos financeiros para as 150 escolas mais bem colocadas no Indicador de Desempenho Escolar (IDE) ${ }^{3}$. De outro lado, o Prêmio busca oferecer apoio financeiro para as 150 escolas com menor desempenho no indicador, como estímulo para que elas consigam alcançar as metas de desempenho estabelecidas pelo Paic.

Além do repasse de recursos financeiros, o Prêmio busca promover um encontro cooperativo entre escolas premiadas e apoiadas. Em cada edição do Prêmio, as 150 escolas que ficaram nas melhores posições 'adotam' as 150 escolas colocadas nas últimas posições do IDE constituindo, assim, parcerias para a implementação das ações de cooperação técnico-pedagógica (GOVERNO DO ESTADO DO CEARÁ, 2009), cujo objetivo principal é melhorar os resultados de desempenho dos alunos nas escolas apoiadas. É por meio dessa cooperação entre escolas (situadas, na maioria dos casos, em munícipios diferentes e nem sempre próximos geograficamente) que o estado do Ceará promove o regime de colaboração horizontal, na medida em que estabelece a parceria entre escolas que precisam construir formas de colaboração para que todas as escolas premiadas e apoiadas mantenham ou alcancem resultados educacionais mais satisfatórios.

Assim, o Prêmio representa um sistema de incentivos sui generis, com peculiaridades que o diferenciam da maioria das iniciativas de bonificação de professores e de premiação de escolas já implementadas no Brasil. Entre essas peculiaridades, está o fato de o Prêmio ser sustentado não apenas em princípios de competição e mérito, como acontece com a maioria das iniciativas estaduais de responsabilização que envolvem repasse de recursos, mas, também, em princípios de colaboração e de equidade, o que o permite discuti-lo a partir da teoria mais geral da justiça como equidade desenvolvida por Rawls (2008) na filosofia política, e retomada por Dubet $(2004,2008)$ e, em certa medida, por Crahay (2002), para tratar do tema específico da justiça escolar.

Para compreender as noções de equidade e de meritocracia subjacentes ao desenho do Prêmio Escola Nota Dez, mobilizamos a concepção de justiça como equidade desses autores na análise das regras e das condicionalidades presentes em documentos referentes à formulação do Prêmio.

O artigo está organizado em duas seções, além dessa introdução e das considerações finais. A $1^{\mathrm{a}}$ seção apresenta a teoria da justiça como equidade de Rawls e as reflexões

${ }^{3} \mathrm{O}$ Indicador de Desempenho Escolar é construído para o $2^{\circ}$ ano do Ensino Fundamental (IDE-Alfa), para o $5^{\circ}$ ano do Ensino Fundamental (IDE 5) e para o $9^{\circ}$ ano do Ensino Fundamental (IDE 9). 
sobre justiça escolar de Dubet e Crahay, com vistas à construção de um aporte teórico que permita testar os argumentos de que a concepção de justiça do Prêmio Escola Nota Dez operaria dentro de uma perspectiva que articula meritocracia e equidade. A $2^{\mathrm{a}}$ seção apresenta as características do Paic e do Prêmio, destacando os principais elementos que se colocam na perspectiva da equidade, com o intuito de evidenciar que uma política de incentivo não é necessariamente inconciliável com uma concepção de justiça redistributiva.

\section{Fundamentos teóricos da justiça como equidade}

A teoria da justiça como equidade de John Rawls (2008) tem sido utilizada por diversos estudos do campo da Educação para investigar a distribuição das oportunidades educacionais e sua relação com as desigualdades (CRAHAY; BAYE, 2014; RIBEIRO, 2012; SOARES; MAROTTA, 2008; VALLE, 2010; WALTENBERG, 2008). Embora muitas críticas se façam à teoria rawlsiana (COHEN, 2001; SANDEL, 1998; SEN, 2011), ela é considerada uma importante referência nos estudos do campo das Ciências Sociais e pode ajudar a pensar as questões da justiça no campo da Educação.

A teoria da justiça como equidade de Rawls (2008) parte da ideia de que a sociedade deve ser organizada a partir de um sistema de cooperação social, na qual todos os membros têm o direito irrevogável às liberdades básicas ${ }^{4}$. Uma vez garantidas essas liberdades, as desigualdades econômicas e sociais, oriundas dessas liberdades, devem ser geridas a partir de dois princípios: a) princípio da igualdade equitativa de oportunidades e b) princípio da diferença - oferta de maior benefício aos membros mais desfavorecidos da sociedade.

Para Rawls (2008), a gestão das desigualdades, a partir de princípios equitativos, só pode ser implementada depois que as liberdades básicas estiverem garantidas a todos os cidadãos. Ou seja, Rawls (2008) entende que primeiro deve-se garantir as liberdades individuais e, depois, a equidade na distribuição das oportunidades - que deve ser aplicada a partir do princípio da diferença.

Isso significa que a competição por postos públicos e posições sociais (RAWLS, 2008) não é aberta e formal, baseada apenas em critérios meritocráticos. Essa competição é regulada por elementos equitativos na medida em que a obtenção

\footnotetext{
${ }^{4}$ As liberdades básicas constituem aquilo que Rawls (2000) chama de bens primários. Elas se apresentam em cinco categorias: 1) As liberdades de pensamento, de consciência etc.; 2) A liberdade de ir e vir e de escolha da ocupação; 3) As capacidades que cada um tem de ascender a posições sociais; 4) Renda e riqueza; 5) Autorrespeito (possibilidades institucionais de exercer suas faculdades morais e de promover seus desejos individuais).
} 
de tais postos e posições deve ser guiada pelo princípio da diferença - oferta de benefícios aos cidadãos menos privilegiados, a fim de garantir condições adequadas para que eles consigam ascender social e economicamente. Assim, a teoria da justiça como equidade entende as desigualdades como aceitáveis, desde que a distribuição das oportunidades beneficie, prioritariamente, os cidadãos menos favorecidos.

Alinhado a esse pensamento - maior benefício aos menos favorecidos -, parte das políticas educacionais brasileiras atuais ${ }^{5}$ tem privilegiado medidas compensatórias ou corretivas para tentar reduzir as desigualdades educacionais. Trata-se de ações de discriminação positiva, pois possuem o objetivo de ofertar mais e melhores oportunidades educacionais àqueles que são socialmente menos favorecidos.

A ideia de uma escola justa é abordada por Dubet (2008, p. 60) a partir do conceito de equidade, sinteticamente definido como "dar mais e, sobretudo, melhor, aos que têm menos". Para Dubet (2004, p. 546), as ações de discriminação positiva promovem equidade educacional, pois limitam "os efeitos dos sistemas meritocráticos cuja mecânica muitas vezes leva à manutenção ou mesmo à acentuação das desigualdades". Assim, embora não se proponha desmantelar o sistema meritocrático, o conceito de equidade, operacionalizado pelas ações de discriminação positiva, pode ser entendido como uma ferramenta corretiva de desigualdades.

A adoção de ações de discriminação positiva em sistemas educacionais meritocráticos é a fórmula encontrada para se tentar promover uma escola mais justa e menos desigual. É nesse sentido que o princípio da diferença da teoria de Rawls (2008) é apropriado pelas políticas educacionais e pelas práticas pedagógicas dos profissionais da Educação.

Como será discutido nesse artigo, argumentamos que o desenho do Prêmio Escola Nota Dez se alinha aos dois princípios de justiça, pois oferece bonificação para as escolas com bons resultados educacionais e apoio técnico e financeiro às escolas com baixos resultados. Nesse sentido, a política educacional do Ceará articula princípios meritocráticos e compensatórios a fim de diminuir a desigualdade de aprendizagem entre os estudantes.

\footnotetext{
${ }^{5}$ A fim de exemplificar, citamos a política de cotas para o acesso ao Ensino Superior e à rede federal de Educação Básica, o Programa Universidade para Todos (Prouni), a Reestruturação e expansão das Universidades Federais (Reuni), o Programa Dinheiro Direto na Escola (PDDE), entre outros.
} 


\section{O Paic}

O Programa foi criado em 2007 como um conjunto articulado de ações que inicialmente visava garantir a alfabetização das crianças até os oito anos de idade. Essas ações foram formuladas com foco no $2^{\circ}$ ano do Ensino Fundamental a partir de 5 eixos: 1) alfabetização; 2) avaliação externa; 3) gestão municipal; 4) Educação Infantil e 5) literatura e formação do leitor. Em 2011, o Paic foi ampliado de modo a incluir o $5^{\circ}$ ano do Ensino Fundamental e, em 2015, o $9^{\circ}$ ano. O objetivo dessa ampliação foi garantir a sustentabilidade da aprendizagem dos estudantes ao longo de todo o Ensino Fundamental. Com essa ampliação, o Paic passou a ter seis eixos de atuação: a) gestão municipal; b) Ensino Fundamental I; c) Ensino Fundamental II e Educação Integral; d) Educação Infantil; e) literatura infantil e formação de leitores; e f) avaliação externa. Cada eixo possui objetivos e metas que foram pactuados entre os atores estaduais e municipais, e qualquer alteração passou a ser acordada entre os envolvidos. Essa é a atual configuração do Paic, que funciona como uma complexa rede de sustentação, manutenção e acompanhamento das ações de implementação da política, por meio da formação continuada de professores, uso de material pedagógico estruturado, formação de gestores e um sistema de avaliação censitário anual - o Sistema permanente de avaliação da educação básica do Ceará (Spaece) - que acompanha os resultados de aprendizagem dos estudantes.

No mesmo ano de criação do Paic, o Spaece ampliou as etapas escolares avaliadas e aplicou testes cognitivos de Leitura e de Matemática para os estudantes do $2^{\circ}$ ano do Ensino Fundamental - etapa referente ao ciclo de alfabetização. Os resultados de 2007 mostraram que apenas 14, dos 184 municípios do estado, conseguiam alcançar o nível de desempenho Desejável na escala de proficiência ${ }^{6}$ da avaliação da alfabetização - o Spaece-Alfa. Por outro lado, a maioria dos municípios cearenses obteve níveis de desempenho Incompleto ou Intermediário, evidenciando a não consolidação da alfabetização das crianças.

Dois anos depois de sua criação, em 2009, foi formulado, no âmbito do Paic, um sistema de incentivo denominado Prêmio Escola Nota Dez, que ainda se encontra em vigor. Tratava-se, na ocasião, de um mecanismo adotado pelo governo estadual para estimular as escolas das redes municipais a priorizarem a etapa escolar referente à alfabetização. Esse mecanismo foi posteriormente reformulado pelas

\footnotetext{
${ }^{6}$ Um dos instrumentos que compõem a avaliação do Spaece é a escala de proficiência, que é dividida em níveis de desempenho. Cada nível de desempenho tem uma interpretação pedagógica, que informa quais os conhecimentos que os estudantes que alcançaram determinado nível dominam. A escala de proficiência, bem como a interpretação dos níveis de desempenho podem ser acessados em: http://www.spaece.caedufjf.net/.
} 
Leis $\mathrm{n}^{\circ} 15.052 / 2011, \mathrm{n}^{\circ} 15.523 / 2015$ e $\mathrm{n}^{\circ} 15.923 / 2015$, e seu foco foi estendido também ao $5^{\circ}$ e ao $9^{\circ}$ ano do Ensino Fundamental, sendo essa, a configuração em vigência. Portanto, a análise aqui empregada refere-se a todo o período (quase 12 anos) em que o Prêmio existe no âmbito do Paic.

Há, pelo menos, dois aspectos que nos permitem dizer que o Paic e, mais especificamente, o Prêmio são ações educacionais diferenciadas.

$\mathrm{O} 1^{\circ}$ deles é a consolidação, na Educação, do regime de colaboração entre os 184 municípios e o governo do estado. O Paic é uma política estadual implementada pelas redes de Ensino Municipal, com um arranjo institucional de implementação (GOMIDE; PIRES, 2014) complexo, que envolve diferentes instâncias políticas e burocráticas, municipais e estaduais. Outro aspecto diferenciado do Paic nas políticas educacionais brasileiras é a coexistência de elementos meritocráticos e equitativos na formulação e na implementação do Prêmio Escola Nota Dez.

\section{O Prêmio Escola Nota Dez}

Para ilustrar o funcionamento do Prêmio Escola Nota Dez, utilizamos o exemplo da alfabetização. O Prêmio se constitui, desde sua experiência original, em 2009, com o ciclo de alfabetização, como uma política indutora da melhoria dos resultados escolares por meio de premiação e de apoio financeiro e técnico às escolas que alcançam, respectivamente, os melhores e os piores resultados no IDE-Alfa ${ }^{7}$, cujo cálculo inclui o nível de proficiência em leitura dos alunos do $2^{\circ}$ ano do Ensino Fundamental das escolas públicas cearenses. O cálculo desse indicador considera, além dos resultados na avaliação do Spaece-Alfa, dois elementos que se alinham ao princípio da diferença (RAWLS, 2008), à ideia de equidade (DUBET, 2004) e ao conceito de discriminação positiva (CRAHAY, 2002).

O $1^{\circ}$ elemento é a taxa de participação na avaliação, que deve ser superior a $90 \%$. Ou seja, para ser elegível ao Prêmio, as escolas devem garantir que pelo menos $90 \%$ dos estudantes façam o teste. Essa medida tem como objetivo combater as práticas de gaming (BROOKE, 2013), muito utilizadas pelas escolas como uma estratégia para melhorar seus resultados educacionais. O gaming é uma ação praticada pelas escolas que orienta estudantes considerados "fracos" a não realizarem o teste para que a proficiência média da escola não seja afetada negativamente e a escola alcance resultados mais altos, contando apenas com a participação dos bons alunos na avaliação. Assim, ao colocar, no cálculo do IDE-Alfa, a elevada

\footnotetext{
${ }^{7}$ Indicador construído com base nos dados do $2^{\circ}$ ano do Ensino Fundamental. O IDE 5 e o IDE 9 referem-se às informações referentes ao $5^{\circ}$ e $9^{\circ}$ anos do Ensino Fundamental, respectivamente.
} 
taxa de participação de $90 \%$ dos alunos na avaliação do Spaece-Alfa, o Paic busca garantir a participação dos estudantes, inibindo práticas de gaming. Pode-se dizer que essa medida se alinha à ideia de discriminação positiva, uma vez que a própria política, formulada a partir de critérios meritocráticos, introduz também critérios de equidade ao exigir uma alta taxa de participação na avaliação, que será capaz de evidenciar as desigualdades de aprendizagem.

Nesse sentido, essa condicionalidade pode ser caracterizada como um mecanismo promotor de equidade, pois inibe a prática do gaming e faz com que a escola se empenhe na garantia da aprendizagem aos estudantes (CRAHAY, 2002), já que $90 \%$ deles precisarão participar da avaliação para a escola poder concorrer ao Prêmio.

$\mathrm{O} 2^{\circ}$ elemento é o fato de ajuste para a universalização do aprendizado, que tem por finalidade estimular as escolas a incluírem um maior percentual de alunos nos níveis de desempenho considerados adequados. Isto é pertinente, pois a média de proficiência da escola não expressa devidamente o grau de universalização do aprendizado (GOVERNO DO ESTADO DO CEARÁ, 2015). Ao estabelecer como critério para a premiação que as escolas tenham a maioria de seus alunos em níveis de aprendizagens considerados adequados, a política estabelece medidas indutoras de equidade que promovem o investimento na aprendizagem de todos os estudantes, principalmente dos mais pobres e daqueles que apresentam mais dificuldades.

Com base nessas informações, o IDE é calculado e utilizado como critério para definir as escolas aptas a receber o Prêmio e, também, as escolas apoiadas, que receberão apoio técnico e financeiro. As escolas premiadas e apoiadas fazem parcerias ou apadrinhamentos para a efetivação do apoio técnico. A partir do IDE, as escolas são ranqueadas e as 150 primeiras colocadas "adotam" as 150 que ficaram nas últimas posições, estabelecendo parcerias que podem durar até dois anos. Essas parcerias se concretizam por meio de ações de cooperação técnico-pedagógica, cujo objetivo é manter ou melhorar os resultados dos estudantes das escolas premiadas e melhorar os resultados dos estudantes das escolas apoiadas.

O valor total da premiação é calculado com base no número de estudantes matriculados no ano escolar premiado $\left(2^{\circ}, 5^{\circ}\right.$ ou $9^{\circ}$ ano). As escolas premiadas recebem o valor de $\mathrm{R} \$ 2.000,00$ por estudante e as escolas apoiadas, $\mathrm{R} \$ 1.000,00$ por estudante. A maior parte do valor recebido é destinada à escola como um todo, e seu uso é normatizado na formulação do Prêmio. Nas escolas premiadas, o dinheiro recebido pode ser utilizado da seguinte forma: 
- Até $20 \%$ pode ser usado para bonificar os professores do ano escolar premiado, profissionais do núcleo gestor e demais profissionais da escola;

- Até $70 \%$ pode ser usado na aquisição de materiais de apoio pedagógico, livros para a biblioteca, formação continuada, reforço escolar, construções, ampliações, reforma e/ou reparos e adequações dos ambientes físicos da escola, material permanente, bem como em outras ações que contribuam para a melhoria da qualidade do Ensino e da aprendizagem dos alunos e

- Até $10 \%$ é destinado ao deslocamento, à alimentação e à hospedagem das equipes escolares para a realização de, no mínimo, seis visitas entre as escolas parceiras. As visitas são implementadas com o objetivo de desenvolver as ações de Cooperação Técnico-Pedagógica junto à escola apoiada (GOVERNO DO ESTADO DO CEARÁ, 2015, p. 18).

Já no caso das escolas apoiadas, a utilização dos recursos obedece a outros critérios:

- Até $90 \%$ do auxílio financeiro é destinado para a melhoria das atividades da escola e

- Até $10 \%$ para as visitas.

Não há, portanto, para as escolas apoiadas, previsão de recursos para a bonificação dos profissionais da escola.

O sistema de parcerias entre escolas presente na formulação e na implementação do Prêmio Escola Nota Dez é um dos componentes inovadores da política educacional do Ceará, pois, por meio de um regime de colaboração horizontal (VIEIRA; VIDAL, 2013), procura articular elementos meritocráticos - prêmio para as escolas com alto desempenho - e elementos de equidade - oferta de apoio técnico e financeiro para as escolas com desempenhos insatisfatórios. Dessa forma, o Prêmio pode ser caracterizado como uma política de promoção da equidade, uma vez que visa favorecer, por meio de auxílio financeiro e técnico, as escolas cujos estudantes obtiveram resultados insuficientes. Ao mesmo tempo em que não estabelece um teto ou um limite, nem constrange ou retarda o desenvolvimento dos estudantes e das escolas que possuem bons resultados. Os "bons" estudantes e as "boas" escolas também são incentivadas a melhorar seus resultados educacionais, por meio do Prêmio. Ou seja, o receio do efeito Robin Hood (CRAHAY, 2002) que faria parte da igualdade de oportunidades (DUBET, 2004), segundo o qual, ao priorizar os menos favorecidos, aqueles 
considerados "bons" seriam prejudicados em seu desenvolvimento, não se verifica no desenho dos incentivos da política educacional cearense. Isto porque o Paic, por meio do Prêmio, incentiva as escolas com bons resultados a perseverarem nessa perspectiva, ao mesmo tempo em que oferece ações de discriminação positiva (CRAHAY, 2002; DUBET, 2004) às escolas que obtiveram resultados insatisfatórios.

Os bons resultados obtidos no IDE e no Spaece mostram que o conjunto de ações do Paic, em especial as condicionalidades presentes na política do Prêmio Escola Nota Dez, vem atuando no sentido de diminuir a desigualdade de conhecimento (CRAHAY, 2002) existente entre as escolas.

Isso pôde ser verificado nos resultados do Spaece. O Spaece-Alfa, por exemplo, mostra evolução significativa na alfabetização. No ano da criação do Paic, em 2007 , apenas $39,9 \%$ das crianças encontravam-se alfabetizadas ao término do $2^{\circ}$ ano; em 2017, esse percentual ampliou-se para 89\% (GOVERNO DO ESTADO DO CEARÁ, 2016, 2019), uma taxa maior do que a do Brasil e do Nordeste (IPECE, 2018).

No $5^{\circ}$ ano, os resultados do Ceará em Língua Portuguesa e em Matemática mostram uma melhora em relação a 2008. Em 2017, 50,3\% dos alunos da rede pública estavam no nível adequado de Língua Portuguesa, enquanto em 2008 eram apenas $6,8 \%$. Em Matemática, 36,7,1\% dos alunos estavam no nível adequado em 2017, enquanto, em 2008, eram somente 3,6\% (GOVERNO DO ESTADO DO CEARÁ, 2019).

O Ideb também permite avaliar em que medida o estado e os municípios atingem as metas projetadas. O Ceará é o estado brasileiro que mais evolui na avaliação do $5^{\circ}$ ano, pois partindo de um Ideb de 2,8, em 2005, alcançou 6,1, em 2017, localizando-se, portanto, acima da média nacional e das metas projetadas para 2017 (4,5 pontos) e para 2021 (5,1 pontos).

Dessa forma, a política educacional cearense conseguiu promover qualidade e equidade, uma vez que avança com a maioria dos estudantes que formam seu público-alvo, no sentido de levá-los a alcançarem resultados satisfatórios.

Outro elemento relevante alinhado à ideia de equidade é a exigência de que $70 \%$ das escolas de um município devem estar no nível Desejável de aprendizado para que uma determinada escola desse município possa ser premiada. Essa medida também busca promover equidade entre as escolas de um mesmo município, já que 
obriga os agentes políticos (prefeitos) e administrativos (gestores educacionais) a dedicar atenção à rede de Ensino como um todo, ao invés de priorizar apenas as escolas consideradas "boas". Nesse sentido, uma escola só pode ser premiada, se a maioria das demais escolas da rede também tiverem resultados satisfatórios. Tal condicionalidade constrange a formação de "escolas gueto" e "escolas santuário" (DUBET, 2004), favorecendo uma baixa variação dos resultados de desempenho entre as escolas - uma das premissas da equidade e da igualdade de conhecimento (CRAHAY, 2002).

A disseminação de boas práticas pedagógicas também é uma característica de destaque no Prêmio. Essa estratégia tem o objetivo de promover a troca e a circulação de experiências exitosas entre as escolas e seus agentes e ocorre, principalmente, nas visitas entre as escolas parceiras, ocasião em que os professores, os coordenadores e os diretores de escolas premiadas e apoiadas encontram o espaço propício para relatar suas experiências.

Essas visitas se configuram como ações de cooperação técnico-pedagógicas, previstas na formulação do Prêmio. Após a divulgação dos resultados do IDE e do Spaece, as escolas são ranqueadas e aquelas que receberão o prêmio e o apoio são definidas. Os agentes envolvidos na gestão do Paic se reúnem com os diretores escolares, no âmbito das Coordenadorias Regionais de Desenvolvimento da Educação (Crede), para estabelecerem as parcerias. Essa troca, atravessada por relações assimétricas entre escolas premiadas (beneficiadas pelo critério do mérito) e escolas apoiadas (beneficiadas em razão de seus resultados insatisfatórios e que, por isso, são foco de iniciativas em favor da equidade), acontece "num processo de mútua ressignificação" (BARROSO, 2011, p. 92). Esse processo envolve a circulação entre as escolas parceiras dos diferentes atores envolvidos com as ações de cooperação técnico-pedagógicas e também a circulação de práticas pedagógicas e de gestão que são ressignificadas em cada contexto escolar por meio da atuação de seus profissionais.

As visitas mútuas entre as escolas premiadas e apoiadas viabilizam a implementação de uma colaboração horizontal (VIEIRA; VIDAL, 2013), por meio de ações de discriminação positiva (CRAHAY, 2002; DUBET, 2004), uma vez que o objetivo das visitas é disseminar boas práticas pedagógicas e de gestão, a fim de fazer com que as escolas apoiadas melhorem seus resultados educacionais.

\section{Considerações finais}

O Prêmio Escola Nota Dez se diferencia das demais políticas de incentivos já implementadas no país por envolver a singularidade de dois conceitos contrastantes. 
De um lado, numa pauta orientada por princípios meritocráticos, está a premiação que estimula a responsabilização e a competição entre municípios e escolas. De outro lado, orientado pelo princípio de equidade, está o apoio técnico e financeiro às escolas de baixo desempenho, que busca reduzir as disparidades de resultados de aprendizagem entre alunos e escolas, promovendo uma aprendizagem considerada adequada entre escolas com maiores dificuldades e que atendem alunos mais desfavorecidos socialmente.

No entrelaçamento desses dois conceitos, o desenho do Prêmio e os resultados do Paic aportam evidências a favor da possibilidade da formulação e implementação de políticas de incentivos que não atendam somente à perspectiva meritocrática de justiça, mas que possam, também, mobilizar a ideia de justiça redistributiva.

Em um contexto como o brasileiro, no qual, de forma recorrente, a melhoria das médias de desempenho está fortemente correlacionada com o aumento da desigualdade dentro e entre as escolas, a experiência educacional cearense mostra que é possível desenhar políticas que incorporem incentivos de forma a ir além da pauta meritocrática do reconhecimento dos bons resultados de escolas e alunos. Essa experiência mostra que políticas educacionais também podem incorporar em seu desenho intervenções baseadas em noções de equidade que, atendendo a uma concepção de justiça corretiva e redistributiva, contribuam para a redução das desigualdades educacionais.

A universalização do direito à Educação de qualidade é um horizonte, um processo complexo, vagaroso, cujo alcance depende de políticas educacionais que colaborem para aumentar o desempenho médio dos alunos, ao mesmo tempo em que promovem uma distribuição social mais equitativa da aprendizagem na escola. 


\title{
Notes for the reconstruction of the notion of equity underlying the Paic design
}

\begin{abstract}
This article aims to analyze the design of the Prêmio Escola Nota Dez, a school award that is part of the incentive system of the Programa Aprendizagem na Idade Certa (Learning at the Right Age Program, Paic by its acronym in Portuguese) of the State of Ceará in the light of Rawls and Dubet's concepts of equity and the concepts of school justice formulated by Crahay and Dubet. To this end, documents referring to the Paic are analyzed in order to explain how these concepts operate in the formulation of the award. In the light of these authors, the article analyzes the sui generis form of how the award combines principles of meritocracy and equity, within the scope of a policy that, like Paic, improves the performance results of students in Portuguese and Mathematics, at the same time that manages to reduce educational inequalities within and between schools in the same educational system.
\end{abstract}

Keyword: Prêmio Escola Nota Dez. Justice as Equity. Meritocracy.

\section{Notas para la reconstrucción de la noción de equidad subyacente al diseño de Paic}

\section{Resumen}

Este artículo tiene como objetivo analizar el diseño del Premio Escola Nota Dez, que se enmarca en el sistema de incentivos del Programa de Aprendizaje en Edad Adecuada (Paic) del Estado de Ceará, a la luz de los conceptos de equidad de Rawls y Dubet. y los conceptos de educación para la justicia y discriminación positiva formulados por Crahay y Dubet. Por tanto, se analizan los documentos referentes al PAIC para explicar cómo operan estos conceptos en la formulación del Premio. A la luz de estos autores, el artículo analiza la forma sui generis del Premio conciliando principios de meritocracia y equidad, en el marco de una política que, como Paic, mejora los resultados del rendimiento medio de los estudiantes en Lengua Portuguesa y en Matemáticas, al mismo tiempo que logra reducir la desigualdad en la distribución social del aprendizaje dentro y entre las escuelas de las redes municipales de enseñanza de Ceará.

Palabras clave: Premio Escola Nota Dez. Justicia como Equidad. Meritocracia. 


\section{Referências}

BARROSO, J. J. Da política baseada no conhecimento às práticas baseadas em evidências. In: OLIVEIRA, D. A.; DUARTE, A. (orgs.). Políticas públicas e educação: regulação e conhecimento. Belo Horizonte: Fino Traço, 2011. p. 91-116.

BRASIL. Ministério da Educação. Parecer do Conselho Nacional de Educação $\mathrm{n}^{\mathrm{o}} 9$, de 30 de agosto de 2011. Análise de proposta de fortalecimento e implementação do regime de colaboração mediante arranjos de desenvolvimento da educação. Diário Oficial da União, Brasília, DF, 22 nov. 2011.

BRASIL. Ministério da Educação. Resolução nº 1, de 23 de janeiro de 2012. Dispõe sobre a implementação do regime de colaboração mediante o arranjo de desenvolvimento da educação (ADE), como instrumento de gestão pública para a melhoria da qualidade da educação. Diário Oficial da União, Brasília, DF, 24 jan. 2012.

BROOKE, N. Sobre a equidade e outros impactos dos incentivos monetários para professores. Estudos em Avaliação Educacional, São Paulo, v. 24, n. 55, p. 34-62, abr./ago. 2013. https://doi.org/10.18222/eae245520132719

COHEN, G. A. If you're an egalitarian, how come you're so rich? Cambridge: Harvard University, 2001.

CRAHAY, M. Poderá a escola ser justa e eficaz? Da igualdade de oportunidades à igualdade de conhecimentos. Lisboa: Instituto Piaget, 2002.

CRAHAY, M.; BAYE, A. Existem escolas justas e eficazes? Esboço de resposta baseado no PISA 2009. Cadernos de Pesquisa, São Paulo, v. 43, n. 150, p. 858-883, dez. 2014. https://doi.org/10.1590/S0100-15742013000300007

DUBET, F. O que é uma escola justa? Cadernos de Pesquisa, São Paulo, v. 34, n. 123, p. 539-555, dez. 2004. https://doi.org/10.1590/S0100-15742004000300002

DUBET, F. O que é uma escola justa? A escola das oportunidades. São Paulo: Cortez, 2008.

GOMIDE, A. A.; PIRES, R. R. C. Capacidades estatais e democracia: a abordagem dos arranjos institucionais para análise de políticas públicas. In: GOMIDE, A.; PIRES, R. (orgs.). Capacidades estatais e democracia: arranjos institucionais de políticas públicas. Brasília, DF: Instituto de Pesquisa Econômica Aplicada, 2014. p. 15-28. 
GOVERNO DO ESTADO DO CEARÁ. Decreto n ${ }^{\circ} 29.896$, de 16 de setembro de 2009. Regulamenta a lei $\mathrm{n}^{\circ} 14.371$, de 19 de junho de 2009 , que cria o prêmio escola nota dez, destinado a premiar as escolas públicas com melhor resultado no índice de desempenho escolar-alfabetização (IDE-Alfa), e dá outras providências. Diário Oficial do Estado, 17 set. 2009.

GOVERNO DO ESTADO DO CEARÁ. Lei no 15.923 , de 15 de dezembro de 2015. Institui o prêmio escola nota dez, destinado a premiar as escolas públicas com melhores resultados de aprendizagem no segundo, quinto e nono anos do ensino fundamental. Diário Oficial do Estado, 16 dez. 2015.

GOVERNO DO ESTADO DO CEARÁ. Portal da transparência. Fortaleza, 2019. Disponível em: https://cearatransparente.ce.gov.br/portal-datransparencia/servidores?locale=pt-BR\&. Acesso em: 3 fev. 2020

GOVERNO DO ESTADO DO CEARÁ. Secretaria da Educação. Sistema permanente de avaliação da educação básica do Ceará (Spaece) 2016: boletim do gestor escolar volume 2. Juiz de Fora: Universidade Federal de Juiz de Fora, 2016.

INSTITUTO DE PESQUISA E ESTRATÉGIA ECONÔMICA DO CEARÁ IPECE. Indicadores sociais do Ceará 2017. Fortaleza, 2018.

MOTA, M. O. Entre a meritocracia e a equidade: o prêmio escola nota dez na percepção e atuação dos agentes implementadores. Tese (Doutorado em Educação) Pontifícia Universidade Católica do Rio de Janeiro, Rio de Janeiro, RJ, 2018.

RAWLS, J. O liberalismo político. São Paulo: Ática, 2000.

RAWLS, J. La justice comme équité: une réformulation de théorie de la justice. Paris: La Découverte, 2008.

RIBEIRO, V. M. Justiça na escola e regulação institucional em redes de ensino do estado de São Paulo. Tese (Doutorado em Educação) - Faculdade de Educação, Universidade de São Paulo, São Paulo, SP, 2012.

SANDEL, M. Liberalism and the limits of justice. Cambridge: Cambridge University, 1998.

SEGATTO, C. I. O papel dos governos estaduais nas politicas municipais de educação: uma análise dos modelos de cooperação intergovernamental. Tese (Doutorado em Administração Pública e Governo) - Escola de Administração de Empresas de São Paulo, Fundação Getúlio Vargas, São Paulo, SP, 2015.

SEGATTO, C. I.; ABRUCIO, F. L. A cooperação em uma federação heterogênea: o regime de colaboração na educação em seis estados brasileiros. Revista Brasileira de Educação, Rio de Janeiro, v. 21, n. 65, p. 411-429, abr./ jun. 2016. https://doi.org/10.1590/S1413-24782016216522 
SEN, A. A ideia de justiça. São Paulo: Companhia das Letras, 2011.

SOARES, J. F.; MAROTTA, L. Desigualdade no sistema de ensino fundamental brasileiro. In: GIAMBIAGI, F. et al. (orgs.). Educação básica no Brasil. Rio de Janeiro: Elsevier, 2008. p. 73-91.

VALLE, I. R. Justiça na escola: das desigualdades justas à igualdade sem adjetivos! In: VALLE, I. R.; SILVA, V. L. G.; DAROS, M. D. (orgs.). Educação escolar e justiça social. Florianópolis: Universidade Federal de Santa Catarina, 2010. p. 19-48.

VIEIRA, S. L.; VIDAL, H. M. Construindo uma história de colaboração na educação: a experiência do Ceará. Educação e Sociedade, Campinas, v. 34, n. 125, p. 1075-1093, out./dez. 2013. https://doi.org/10.1590/S0101-73302013000400004

WALTENBERG, F. Quatre grandes écoles pour penser la justice dans le champ de l'éducation. In: DUPRIEZ, V.; ORIANNE, J. F.; VERHOEVEN, M. (orgs.). De l'école au marché du travail, l'égalité des chances en question. Bern: Peter Lang, 2008. p. 25-52.

\section{Informações sobre as autoras}

Naira Muylaert: Doutora em Educação pela Pontifícia Universidade Católica do Rio de Janeiro. Professora Assistente do Programa de Pós-Graduação em Educação da mesma universidade. Contato: naira@puc-rio.br

(iD https://orcid.org/0000-0001-5161-0501

Alicia Maria Catalano de Bonamino: Doutora em Educação pela Pontifícia Universidade Católica do Rio de Janeiro. Professora Associada do Programa de Pós-Graduação em Educação da mesma universidade. Bolsista Produtividade em Pesquisa do CNPq - Nível 1C. Contato: alicia@puc-rio.br

(iD) http://orcid.org/0000-0001-8778-5362

Maria Océlia Mota: Doutora em Educação pela Pontifícia Universidade Católica do Rio de Janeiro. Orientadora Educacional da Secretaria Municipal de Educação de Duque de Caxias/RJ. Contato: oceliamota@gmail.com

iD http://orcid.org/0000-0002-3927-6261 